\title{
Doblemente desaparecidos: servicio militar, pobreza y represión en la frontera patagónica durante la última dictadura argentina ${ }^{1}$
}

\begin{abstract}
Resumen
En las últimas décadas, la lucha de los organismos de derechos humanos en Argentina ha logrado importantes avances judiciales y de políticas públicas vinculadas a la memoria, la verdad y la justicia respecto de las atrocidades cometidas bajo el terrorismo de Estado. Actualmente, asistimos a la pretensión oficial de reinstalar el discurso negacionista, ante lo cual, desde el campo académico, la historia oral y los estudios sobre memorias permiten iluminar aspectos novedosos que demuestran la falacia de dicho discurso, a la vez que enriquecen la mirada sobre ese pasado que no pasa. Desde esta perspectiva, y basado en testimonios orales y documentos de archivo, este artículo aborda el caso de Héctor Domingo Inalef, detenido en El Bolsón por supuesta deserción al servicio militar en 1976 y desde entonces "desaparecido" hasta reencontrarse con su familia en 2014. Hijo mayor y principal sostén económico de una familia mapuche tradicionalmente dedicada al acopio y acarreo de leña, su historia abona la reflexión sobre la desaparición forzada en nuestro país, la superposición de la represión con las marcas de la desigualdad social, y las implicancias políticas y memoriales de la pobreza y la ruralidad en la frontera patagónica, tanto en tiempos dictatoriales como democráticos.
\end{abstract}

Palabras clave: Desaparecidos Políticos. Servicio Militar.

Patagonia - Historia. Pobreza.

\author{
Marina Ayelen Mereb \\ Doctora en Ciencias Sociales por la \\ Universidad Nacional de La Plata. \\ Investigadora del Grupo de Estudios de \\ Historia Reciente y Memorias Sociales. \\ Instituto de Investigaciones Gino \\ Germani. Universidad de Buenos Aires. \\ Buenos Aires - ARGENTINA \\ ayemereb@yahoo.com.ar \\ orcid.org/0000-0002-4201-7789
}

\section{Para citar este artículo:}

MEREB, Marina Ayelen. Doblemente desaparecidos: servicio militar, pobreza y represión en la frontera patagónica durante la última dictadura argentina. Tempo e Argumento, Florianópolis, v. 11, n. 28, p. 47 - 66, set./dez. 2019.

\section{DOI: $10.5965 / 2175180311282019047$}

http://dx.doi.org/10.5965/2175180311282019047

\footnotetext{
${ }^{1}$ Este artículo fue elaborado a partir de la investigación realizada para mi tesis doctoral, en la Universidad Nacional de La Plata, dirigida por el Dr. Emilio Crenzel y posible gracias al financiamiento del Consejo Nacional de Investigaciones Científicas y Técnicas (CONICET) de Argentina. Agradezco especialmente la lectura atenta y los comentarios pertinentes de los evaluadores anónimos y de Pablo Scatizza a una versión borrador de este artículo, así como a Andrea del Valle Bazán y Sofía Martin por sus traducciones.
} 
Doubly-missing people: military service, poverty, and repression on the Patagonian border during the last Argentine dictatorship

\begin{abstract}
In recent decades, the struggle of human rights organizations in Argentina has made major judicial and public policy advances linked to memory, truth, and justice regarding the atrocities committed under State terrorism. Currently, we witness the official aspiration to reinstall the denialist discourse, whereby, starting from the academic field, oral history and studies on memories allow us to illuminate novel aspects that demonstrate the fallacy of such a discourse, while enriching the look on this past that does not get over. From this perspective, and based on oral testimonies and archival documents, this article addresses the case of Héctor Domingo Inalef, detained in El Bolsón for alleged desertion from military service in 1976 and since then 'missing' until he met his family again in 2014. Eldest son and main economic support of a Mapuche family traditionally dedicated to the collection and carrying of firewood, his history improves the reflection on forced disappearance in our country, the overlap of repression with the marks of social inequality, and the political and memorial implications of poverty and rurality on the Patagonian border, both in dictatorial and democratic times.
\end{abstract}

Keywords: Missing People for Political Reasons. Military Service. Patagonia - History. Poverty.

\section{Duplamente desaparecidos: serviço militar, pobreza e repressão na fronteira patagônica durante a última ditadura argentina}

\begin{abstract}
Resumo
Nas últimas décadas, a luta das organizações de direitos humanos na Argentina fez grandes avanços judiciais e de políticas públicas vinculadas à memória, verdade e justiça em relação às atrocidades cometidas sob o terrorismo de Estado. Atualmente, testemunhamos a aspiração oficial de reinstalar o discurso negacionista, segundo o qual, a partir do campo acadêmico, a história oral e os estudos sobre memórias permitem que iluminemos novos aspectos que demonstram a falácia de tal discurso, enquanto enriquecem o olhar sobre esse passado sem fim. A partir dessa perspectiva, e com base em testemunhos orais e documentos de arquivo, este artigo trata do caso de Héctor Domingo Inalef, detido em El Bolsón por suposta deserção do serviço militar em 1976 e desde então "desaparecido" até se reunir com sua família em 2014. Filho mais velho e principal suporte econômico de uma família mapuche tradicionalmente dedicada à coleta e ao transporte de lenha, sua história aprimora a reflexão sobre o desaparecimento forçado em nosso país, a sobreposição da repressão com as marcas da desigualdade social e as implicações políticas e memoriais da pobreza e da ruralidade na fronteira da Patagônia, tanto em tempos ditatoriais quanto democráticos.
\end{abstract}

Palavras-chave: Desaparecidos Políticos. Serviço Militar. Patagônia - História. Pobreza. 


\section{Introducción}

En las últimas décadas, la lucha de los organismos de derechos humanos en Argentina ha logrado importantes avances judiciales y de políticas públicas vinculadas a la memoria, la verdad y la justicia respecto de las atrocidades cometidas en torno a la última dictadura militar. Actualmente, asistimos a la pretensión oficial de reinstalar el discurso negacionista, ante lo cual -desde el campo académico-, la historia oral y los estudios sobre memorias permiten iluminar aspectos novedosos que demuestran la falacia que esto supone, a la vez que enriquecen la mirada sobre ese pasado que no pasa (FRANCO; LEVIN, 2007). Desde las posibilidades que nos brinda la microhistoria para abordar los fenómenos sociales alterando la escala de observación (GINZBURG, 1994; LEVI, 1996), y a través de una historia de vida particular, este artículo busca aportar elementos en ese sentido.

Se trata de la historia de Héctor Domingo Inalef, un joven mapuche que a los 18 años de edad y en plena dictadura, fue arrestado por orden del Ejército en la vivienda que habitaba junto a su madre, su padre, y sus varios hermanos y hermanas menores, acusado de desertor al Servicio Militar Obligatorio. El hecho ocurrió en el verano de 1976-77, en la zona rural de Mallín Ahogado, en las cercanías de El Bolsón (provincia de Río Negro), cordillera patagónica. De modo muy violento, lo subieron a un camión y se lo llevaron a la vista de su familia, dejando el recuerdo profundamente marcado en la memoria de Zunilda, su hermana menor que entonces tenía apenas 2 años de edad. La familia no volvió a saber de él. La comunidad local desconoció lo ocurrido.

En 2013, y en el marco de la emisión especial de una radio comunitaria en conmemoración del $37^{\circ}$ aniversario del último Golpe de Estado, Zunilda reconstruyó esta historia públicamente por primera vez. O más bien segunda, ya que meses antes lo había hecho en un Encuentro de Mujeres celebrado en un centro comunitario barrial, un ámbito más íntimo que la animó a empezar a exteriorizar sentires profundos que traía consigo desde hacía casi cuatro décadas. En un contexto regional y nacional favorable a las reivindicaciones en materia de derechos humanos, pero también a las de los movimientos indigenistas y feministas que atraviesan esta historia, estos escenarios habilitarían el surgimiento de esas memorias subterráneas de las que habla Pollak (2006), que, 
En la radio la entrevistaba Iris, su maestra de la escuela de adultos en la que Zunilda completó sus estudios primarios a los casi 40 años de edad; la maestra con quien aprendió sobre el período dictatorial, pudiendo establecer conexiones con su propia vivencia. Entonces, compartiría el pesar que la había acompañado toda su vida a raíz de la incertidumbre sobre el destino de su hermano, así como las dificultades atravesadas por la familia ante la desprotección que supuso su ausencia, incluyendo dos violentos desalojos de los campos ocupados tradicionalmente por sus ancestros:

Los recuerdos esos que tengo fue durante el día. Recuerdos feísimos que se me quedaron... bah, nunca más se me van a borrar. De esa vez nunca más supe de mi hermano. Hasta el día de hoy, ya más o menos debe tener como 55 años a esta altura [...] Yo recuerdo que llegaron y se lo llevaron, apuntado con un arma... ese recuerdo lo tengo. Eran 4, 5 gendarmes más o menos. De militares, porque andaban con ropa verde me acuerdo... y un camión grande... tenía una lona verde. (Z. INALEF, 2013, información oral)

Conocí esta historia mientras trabajaba en la investigación para mi tesis doctoral sobre historia y memorias de la represión política en El Bolsón, una localidad en la que, según la narrativa hegemónica, en dictadura "no pasó nada" o a lo sumo "no se sintió tanto". Si bien el entramado que fui reconstruyendo a través de una diversidad de fuentes orales y documentales me permitía ya demostrar la falacia de tal afirmación², la historia que se me presentaba traía aparejados nuevos e insospechados pliegues que agregaban densidad al fenómeno en estudio. Máxime cuando pocos meses más tarde, por confluencia de circunstancias entre las que también intervino la investigación académica, Zunilda confirmó que su hermano Héctor efectivamente estaba vivo y residía en la ciudad de Viedma - capital rionegrina -, produciéndose por fin el ansiado reencuentro familiar. Las derivaciones del caso resultan sumamente enriquecedoras tanto para el conocimiento y la comprensión de la trama local, como para la reflexión académica en torno a los trabajos de memorias - y olvidos - sobre nuestra historia reciente, no sólo argentina sino también latinoamericana.

\footnotetext{
${ }^{2}$ Una reseña de lo acontecido puede leerse en Mereb (2018).
} 
Encuadrado en los estudios de memorias sociales sobre pasados traumáticos, cuyo mayor desarrollo se ha centrado en los procesos nacionales y sus manifestaciones en los sectores medios y politizados de las principales urbes del país, este artículo busca dialogar principalmente con aquellos trabajos que ponen el acento en la escala local. Como señalan Jensen y Águila (2017, p. 7), tales producciones han proliferado a partir de la

[... ] necesidad de complejizar la mirada desde la apelación a otras escalas espaciales y analíticas que permitan descubrir nuevos sujetos, nuevas periodizaciones, nuevos problemas y nuevas explicaciones desde la asunción de las potencialidades - nunca exclusivas ni excluyentes - de lo local, lo regional, lo transnacional y lo comparado.

En este sentido, y citando a Del Pino y Jelin (2003, p. 1), las autoras destacan la construcción de una agenda de temas y problemas atenta a "comunidades locales, en su mayor parte ubicadas territorial, simbólica y/o políticamente 'lejos' de las ciudades capitales y los procesos centrales", así como desde enfoques comparativos que permitan pensar las experiencias puestas en diálogo.

Específicamente para la región patagónica, este trabajo busca abonar al propósito de Scatizza (2019) en cuanto a la importancia de desentrañar las particularidades que el plan sistemático de aniquilamiento asumió en espacios geográficos periféricos a la lógica concentracionaria descripta por Calveiro (1998). Como propone Colombo (2017), considerar el fenómeno de la desaparición en términos de espacios múltiples, constelaciones que vinculan una diversidad de situaciones, en las que la técnica de la desaparición forzada se implementó de manera diferencial según se tratara de ámbitos rurales o urbanos, derivando a su vez en modos diferentes de narrar lo sucedido.

Advierte por ello la autora que abordar las violencias políticas y el terrorismo de Estado desde las memorias rurales permite incorporar dimensiones novedosas sobre las que conviene profundizar. En este sentido, Merenson y Garaño (2015, p. 20) señalan que se trata muchas veces de memorias menos encuadradas, por momentos políticamente incorrectas en cuanto a que "no siempre se ajustan a las perspectivas de los actores socializados en el lenguaje de los derechos humanos, ni se acoplan fácilmente a los relatos hegemónicos nacionales y/o de los centros". Se trata de memorias que circulan de 
experiencias de grupos empobrecidos que no fueron portavoces principales del pasado de violencia política, los autores llaman la atención sobre la importancia de identificar en sus relatos "las huellas que ha dejado el activo trabajo de producción de hegemonía en los espacios rurales" (MERENSON; GARAÑO, 2015, p. 21).

Finalmente, el caso presenta el desafío de pensar en términos de memorias indígenas que, como demuestra la compilación realizada por Ramos, Crespo y Tozzini (2016, p. 10), remiten a "grupos cuya vocalidad ha sido históricamente silenciada, construidos como otros internos u otros externos por las narrativas de una nación imaginada como blanca y homogénea”. Desde el genocidio que supuso la denominada “Conquista del Desierto" y a lo largo de todo el siglo XX, el pueblo mapuche ha sido estigmatizado, excluido, reprimido y saqueado por el Estado en manos de la burguesía comercial y terrateniente nacional. La historia que aquí presento nos convoca a seguir reflexionando sobre los procesos de subordinación y violencia atravesados por las comunidades originarias en la frontera patagónica, trascendiendo incluso las alternancias entre gobiernos constitucionales y de facto.

Con el afán de sumar a la construcción permanente de la memoria colectiva sobre nuestro pasado reciente, propongo pensarla como caso testigo de aquellos "doblemente desaparecidos", en tanto sus nombres no figuran ni en las burocracias estatales, ni en los registros de los organismos de derechos humanos, toda vez que las carencias materiales y simbólicas propias de la pobreza estructural impidieron llevar adelante denuncia o acción política alguna en pos de conocer el destino de las víctimas perpetrado por la violencia estatal. Invito con ello a profundizar reflexivamente en el vínculo poco explorado entre represión y pobreza, en la experiencia de aquellas víctimas cuyo padecimiento no estuvo ligado a activismo político alguno, sino al mero hecho de pertenecer a los sectores más vulnerables de la estructura social. Dar cuenta así de la potencia de la historia oral y la microhistoria para iluminar complejidades que de otro 


\section{"A nosotros nos vendieron con campo y todo, adentro"}

El relato radiofónico me permitió desandar una trama que me llevó a des-cubrir otra que estaba oculta y que fue emergiendo en la medida en que se la empezó a nombrar. Señala Pollak (2006, p. 20) “el largo silencio sobre el pasado, lejos de conducir al olvido, es la resistencia que una sociedad civil impotente opone al exceso de discursos oficiales". Algo - o mucho - de eso parecía envolver esta experiencia.

Pude encontrarme con Zunilda casi un año más tarde de aquella entrevista radial. Conversamos sobre el arribo de su familia a estas tierras a comienzos de siglo, coincidentemente con las oleadas migratorias que supuso la desestructuración del mundo indígena tras las campañas militares de los estados argentino y chileno; las actividades agropecuarias a las que tradicionalmente se habían dedicado, especialmente acopio y acarreo de leña; su infancia en una familia numerosa y empobrecida en los años 1970, mientras el centro urbano más cercano, El Bolsón se consolidaba como destino turístico; el analfabetismo de sus padres y la consecuente vulnerabilidad ante los sectores de poder, las dificultades para estudiar y la incompatibilidad con la necesidad de que todo el grupo familiar trabajase. Respecto del episodio protagonizado por Héctor, Zunilda reconstruyó:

El recuerdo más feo que tengo es de cuando los militares se lo llevaron a mi hermano mayor. Cuando a él lo llevaron entraron a mi casa, tengo esos recuerdos que yo andaba jugando ahí afuera, y de repente paró el camión de gendarmería y se bajaron unos todos de verde, con armas [...] Y yo me fui corriendo a la cocina... cuando fui corriendo a la cocina ellos llegaron $y$ pasaron y sacaron a mi hermano, mi hermano así escondido en la pieza y... hablaron con mi viejo y después lo fueron a sacar, del brazo lo sacaron a mi hermano, de ahí se lo llevaron [...] Apuntándolo con eso, sí. Pero no sé por qué, por eso yo le decía más antes a mi viejo "¿por qué se lo llevaron así?" y mi viejo decía "porque se negó a hacer el servicio militar, era infractor a la ley" [... Estaban mi papá y mi mamá en ese momento... se quedaron los dos en la cocina. Nunca dijeron nada, porque al ver que lo llevaban con las armas, no dijeron nada, pero no sé si hubo forcejeo o no... yo era muy chica. (Z. INALEF, 2014a, información oral) 
Los hechos sucedieron en el paraje rural de Mallín Ahogado, una comunidad en ese entonces pequeña, empobrecida, periférica y sometida al autoritarismo estatal propio de las áreas fronterizas. Instituciones como la gendarmería, la escuela, la policía o la iglesia se erigían en guardianas de la reserva moral, el orden y el progreso civilizatorio frente al "atraso" indígena. Como han trabajado diversas autoras (BANDIERI, 2009; MENDEZ, 2011; TOZZINI, 2012, entre otros investigadores), tras la denominada "Conquista del Desierto" y a lo largo del siglo XX, la estigmatización y la represión sobre el pueblo mapuche acabó por disciplinar dicha identidad al punto de silenciarla durante varias décadas, incluyendo los años que nos ocupan. Junto a la violencia con que se perpetró la detención, Zunilda relaciona la nula reacción de sus padres, e incluso de vecinos y otros familiares, a "la falta de estudio", lo que se traducía en escasez de recursos simbólicos para reclamar ante las violencias y la sumisión que esto suponía frente a la autoridad y la naturalización de sus abusos.

Desde entonces, y sin uno de los pilares fundamentales de la economía doméstica, la familia sufrió un proceso de deterioro y desmembramiento producto de las carencias estructurales, que se tradujo en las trayectorias errantes de varios de sus integrantes. Pero el hecho destacado en el relato de Zunilda es cuando se produjo el primero de los desalojos perpetrados con prepotencia y abuso de poder en nombre de una propiedad privada que no les reconocía como legítimos ocupantes. Notable acusación, toda vez que se trataba de una familia a la que, según indica Sales (2002, p. 96), por disposición de la Dirección de Tierras y Colonias, en 1972, se le había otorgado para su radicación exclusiva la superficie que ocupaban de manera ininterrumpida desde principios de siglo; una familia cuya presencia incluso fuera destacada por las primeras autoridades escolares, en 1938, cuando al referir a la fundación del establecimiento en el paraje caracterizado como “inhóspito y aislado”, “librado a su propio albedrío y justicia”, señalaban que

[...] en este medio y circunstancias lucharon los primeros pobladores pudiendo citar a las familias: Quisle - Muñoz - Inalef - Rogel; que desde hace más de tres décadas luchan en estos parajes y que en la medida de sus recursos han contribuido al surgimiento de las escuelas. (LIBRO HISTÓRICO ESCUELA Nº118, 1938, p.12. La cursiva es mía) 
Según el relato familiar, el operativo ocurrió en tiempos dictatoriales, fue llevado a cabo por la gendarmería y la policía rionegrina, y habría sido impulsado por los primos de Zunilda, que, aunque nunca habían vivido en el campo, se atribuían derechos sobre las tierras según una titularización realizada en condiciones poco claras. El evento ocurrió en un contexto regional en el que, como indica Tozzini (2012), la organización corporativa de la actividad forestal impulsada desde el Estado en toda la zona cordillerana del sudoeste de Río Negro y noroeste del Chubut en los años 1970, sirvió como locus de anexión al sistema capitalista de territorios marginales, ocupados por antiguos pobladores sin título de propiedad. Ya sea por ubicación, por potencialidades productivas o turísticas, bellezas paisajísticas o recursos naturales, señala la autora que a medida que fue aumentando la valorización económica, determinadas tierras periféricas pasaron a ser objeto del negocio inmobiliario, aumentando la presión sobre sus históricos ocupantes a través de distintos actores sociales, entre ellos empresarios, políticos, terratenientes, particulares con poder o agencias estatales. En este marco, lejos de resultar una excepción, el caso de los Inalef se asemeja a los innumerables desalojos perpetrados por el Estado contra familias campesinas y mapuches con presencia centenaria en los campos, que sólo disponían de un "permiso de ocupación y pastaje", que no garantizaba dominio definitivo, y por el contrario, se extinguía ante el fallecimiento del titular, pasando los ocupantes a ser considerados "usurpadores". En aquella oportunidad, la familia Inalef fue desplazada a un rincón del campo e incendiada la vivienda ocupada desde antaño. Alrededor de 15 años más tarde, y tras la muerte de su padre, la propia Zunilda se vería envuelta en una situación similar, teniendo que abandonar el campo por segunda vez, ahora con sus pequeñas hijas, bajo una nueva acusación por “intrusa en propiedad privada”. En sus palabras:

Nosotros no vendimos nada. A nosotros nos quitaron las tierras y nos dejaron así de brazos cruzados. Encima que nos hicieron dos desalojos, a mí me desalojaron con mis hijas. La policía fue y nos sacó... [...] Todo a escondidas, como hacen todo a escondidas cuando uno no tiene estudios, nada, te pasan por encima. A nosotros nos vendieron con campo y todo, adentro. Después vino el desalojo que se hacía porque ya estaba vendido, por eso nos tuvimos que retirar nosotros, a la fuerza, y el ranchito que teníamos lo tiraron todo a la mierda. Los árboles, la evidencia, todo está. (Z. INALEF, 2014b, información oral) 
Ante lo recurrente de esta operatoria, Tozzini (2012) señala que, en muchos casos y por diversos motivos, los pobladores desplazados no hicieron pública su historia, directamente vinculada al proceso de desarticulación del mundo indígena y la dispersión resultante en la región. Adquiere por ello mayor trascendencia el ímpetu de Zunilda por dar testimonio de la propia experiencia, como indica Pollak (2006), algo posible sólo en la medida en que se dan las condiciones para hacerla comunicable. Entonces sí correr el velo del silencio, y poner palabras que rescaten las vivencias del olvido aparente, desde marcos de significación renovados, incorporando elementos hasta aquí ajenos a la experiencia personal y familiar para accionar de un modo novedoso.

“Me agarraron, me llevaron, me dejaron... como a un verdadero delincuente"

Confluencia de esfuerzos y circunstancias, en otoño de 2014 se produjo el ansiado reencuentro con Héctor. Viajaron a Viedma Zunilda, dos hermanas y su mamá. Hubo nervios, llantos, abrazos y pocas palabras. “Me preguntó si estaba todavía en el campo que él... en donde lo sacaron los militares. Yo le dije que no, que hay unos alemanes. ¡Estaba re caliente!", contó Zunilda (2014b, información oral) al regresar. En esa segunda entrevista, cargada de novedades emotivas e intensas, le dejé los datos del Archivo Provincial de la Memoria de Río Negro para que se los enviara a su hermano, entendiendo que allí podrían asesorarlo sobre los derechos vulnerados. Un año más tarde y con la compañía de su hija, Héctor se comunicó con el Archivo, lo que derivó en sucesivos encuentros con el equipo técnico, a partir de los cuales pudieron armar un relato sobre lo sucedido, tanto para el propio Archivo como para los trámites de leyes reparatorias e incluso la posibilidad de iniciar una denuncia penal por los padecimientos sufridos.

Primero conocí ese testimonio fechado en noviembre de 2015, y en mayo de 2016 pudimos conversar personalmente con Héctor en Viedma. Entonces reafirmé lo emblemático del caso en cuanto a los alcances que tuvo el andamiaje legal e ilegal de la represión en esa zona cordillerana que aún se pretende alejada y ajena al terrorismo de Estado. 
Clase 58, Héctor fue sorteado para hacer el servicio militar en 1976. Como pude corroborar, en su documento nacional de identidad ha quedado asentado el reconocimiento médico realizado en noviembre de ese año, cuyo resultado "Apto A" está firmado y sellado por el Teniente Coronel Miguel A. Padilla Tanco, máxima autoridad del Distrito Militar Río Negro en ese momento. Según su relato, esa temporada Héctor estaba trabajando con su padre en la vecina localidad de El Maitén. "Laburábamos una semana, después nos íbamos, después el tipo nos avisaba de vuelta"; entonces estaba en el domicilio familiar en Mallín Ahogado cuando "ahí me fueron a buscar, llegaron, me subieron arriba y listo" (H. D. INALEF, 2016, información oral). Dentro de la zonificación militar establecida por la Doctrina de Seguridad Nacional, Mallín Ahogado integraba el Área 524, cuya Jefatura tenía asiento en la Escuela de Instrucción Andina del Ejército en Bariloche, a cargo del Coronel Néstor Rubén Castelli. Acusado de desertor, a Héctor lo fueron a buscar y lo arrastraron "con lo puesto", apuntado con armas largas frente a sus padres, hermanos y hermanas menores, "como un verdadero delincuente". Como él mismo reconstruyera cuando brindó testimonio por vez primera por haber estado detenido sin causa ni juicio ni condena entre 1976 y 1978 :

Yo estaba por hacer el servicio militar y justo 2 días antes de la fecha que me tenía que presentar, me sacan de mi casa y me traen y me dejan acá, ¡directamente! Tenía 18 años. Vivía en Mallín Ahogado. Cuando me sacaron de allá, me trajeron esposado como si fuera un delincuente. Me sacan en un camión del Ejército y me llevan a Bariloche, y ahí me tuvieron como 304 meses, me parece. Me tuvieron encerrado en un calabozo. $Y$ después me trasladaron para acá [Viedma], también esposado, cada vez que tenía que ir al baño tenía un milico a la par. Cuando abrían la puerta me sacaban las esposas, cuando me sacaban me las ponían de vuelta. Nunca me llamaron a declarar. Me trajeron directamente y me dejaron acá en la Comisaria Primera. Nunca vi a un juez. Nadie se comunicó conmigo. (H. D. INALEF, 2015, información oral)

Con el relato contado por su protagonista, empezaron a aparecer retazos de una trama hasta aquí desconocida, relativa a la organización regional de la represión: por ejemplo, que en el camión había más personas, y que en el lugar donde lo metieron “traían de todos lados, era una multitud”; que de la Escuela de Instrucción Andina lo llevaron esposado a Viedma en el tren, y allá "lo tenían para limpiar los baños, para todas esas cosas lo tenían" (Z. INALEF, 2014b, información oral). Héctor no tenía participación 
arbitraria para cumplir tareas de servidumbre durante casi dos años. Todo esto además en tiempos dictatoriales, conjurándose así la superposición de las dos tramas de violencia estatal que analiza Garaño (2016) para el Operativo Independencia en Tucumán: por un lado, la de la propia conscripción en cuanto rito oficial de pasaje masculino a la adultez, a la ciudadanía argentina, configurado a partir de la institucionalización de prácticas, rutinas y rituales basados en el desprecio por la vida de los soldados y la naturalización de torturas, castigos y arbitrariedades, máxime tratándose de varones pobres de la periferia de los centros de poder; peor aún si eran desertores, considerados no merecedores de derechos, más vulnerables a las violencias del Estado. Por el otro lado, la del estado de excepción que suponía la imposición del gobierno militar y su capacidad de dar muerte, ya sea de opositores políticos como de conscriptos “rebeldes". Durante el tiempo que duró su detención ilegal, Héctor fue víctima y testigo de numerosos atropellos y atrocidades, entre los que Zunilda recordaba que les había hablado de una persona "que es de Bariloche y nunca más lo encontramos, pero él dice que lo hicieron boleta a ese chico" (Z. INALEF, 2014b, información oral).

Confinado en un calabozo de la Escuela de Instrucción Andina en Bariloche, incomunicado y sin posibilidad de recibir visitas, si Héctor preguntaba algo le respondían: "vos vas a estar acá y después te vamos a trasladar a Viedma", donde "es jodido, hay que tener cuidado, estos matan nomás..." (H. D. INALEF, 2016, información oral). Mediante el terror como tecnología disciplinadora, durante esos tres meses lo hicieron limpiar pisos y cuando finalmente lo subieron esposado al tren, se encargaron de reforzar la amenaza: "te vas a Viedma porque sos un desertor, no sé qué van a hacer con vos ahora" (H. D. INALEF, 2016, información oral). Allí lo esperaba un camión del Ejército, en el que lo Ilevaron a la Comisaría Primera de la Policía rionegrina: "por orden del teniente Padilla Tanco, que me dejen en la comisaría, que después yo les voy a avisar qué hay que hacer con éste [... Me dejaron ahí... y ahí estuve un año y ocho meses, o algo así...en total dos años me tuvieron..." (H. D. INALEF, 2016, información oral). 
Sobre el tiempo en el calabozo, recuerda el trato violento hacia los presos en general, entre los que había desde detenidos por contravenciones hasta presos que estaban cumpliendo condenas. En su caso particularmente, "me maltrataban, me insultaban, pero como yo no les decía nada... [... ] yo no estaba como desertor porque todavía no se había cumplido la fecha en que me tenía que presentar" (H. D. INALEF, 2015, información oral). Al indicar que su destino era Bariloche, remarcó: "yo la pensaba hacer, si lo mejor que hay es hacer la colimba" (H. D. INALEF, 2015, información oral), reafirmando el status del que la tradición castrense gozaba entre los varones de su generación. Quizás por eso también la injusticia sería superlativa, ya que durante todo el tiempo que estuvo detenido fue obligado a limpiar pisos y baños "así te ganás la comida", según lo amenazaba el oficial Lobos, que era "el jefe, el que se metía adentro a patotear, me acuerdo la cara de ese" (H. D. INALEF, 2015, información oral).

Sin ningún tipo de señal ni anuncio previo, la liberación estuvo envuelta por la misma desidia y destrato con que lo habían mantenido recluido:

\begin{abstract}
Un día vino uno del ejército con unos papeles. Me mandaron, me dijeron "vos tenés que irte a Bahía Blanca al Batallón 181". Me fui solo, me dijo uno que me atendió "te vas a ir solo, no te escapes porque no salís más". Me fui solo en un tren. Llegué a Bahía, pá colmo no conocía nada si...[...] Me llevaron ahí, me revisaron unas pibas ahí, en el Ejército, después pasás donde te revisan los hombres. Habré estado una hora y media más o menos ahí adentro... y ahí me dijeron "tás listo, andá nomás". Me dice "pasá por la oficina, esperá, te van a dar un pasaje para Viedma". Los papeles no sé lo que decían, tampoco los estuve mirando. Pasé por la comisaría de vuelta y me dijeron "bueno, ya está, ¿ya fuiste a Bahía?", me atendió el oficial. Sí, le digo. "Bueno, ya ahora andate nomás, andate, pero no vas a estar haciendo cagadas porque te vas a quedar adentro de vuelta." Así. (H. D. INALEF, 2016, información oral)
\end{abstract}

Al respecto y como pude ver en su DNI, justo a continuación del "Apto A" que le habían asignado en el reconocimiento médico en Bariloche, la sección "excepción al servicio" tiene un sello y está fechada el 15 de marzo de 1978. Como causa figura un número de expediente según el inciso $1^{\circ}$ del artículo 32 de la Ley de Servicio Militar (ARGENTINA, 1967), que indica la excepción para aquellos ciudadanos que "al momento de su convocatoria se hallaren comprendidos en las causales siguientes: $1^{\circ}$ ) Los que por enfermedad o defecto físico resulten ineptos en forma absoluta y definitiva para el 
General del Ejército, se les negó la existencia de documentación alguna vinculada al caso. Tampoco hubo respuesta desde el Juzgado Federal de Viedma ni el Ministerio de Seguridad. Abono con ello la hipótesis de Scatizza (2019) acerca de la trascendencia de los “centros de detención clandestina” en regiones relativamente periféricas a la dinámica concentracionaria descripta por Calveiro (1998): a diferencia de los centros clandestinos de detención, se trataba de lugares públicos en los que todo funcionaba bajo aparente normalidad, mientras ocurrían detenciones ilegales cuyas víctimas no eran debidamente registradas, alimentando una trama que debe ser profundizada para mostrar la complejidad y la sistematicidad del plan represivo.

Las amenazas propinadas al momento de la liberación reforzarían el efecto de terror y de disciplinamiento propio de la tecnología de la desaparición. Tal como analiza Lampasona (2013), así como la desaparición/eliminación constituyó uno de los nudos centrales del poder genocida, también lo fue el par desaparición/aparición, menor en términos cuantitativos, pero con efectos performativos sobre la realidad impuesta. La secuencia de la desaparición interrumpida por la liberación y posterior sobrevida, señala la autora, tendería a consolidar los efectos del terror, ya sea por contar acerca de los padecimientos o, peor aún, por tener que ocultarlos a fuerza de cuestionamientos, estigmatizaciones e imposibilidades de escucha de parte del entorno inmediato (CRENZEL, 2008).

Y ahí me liberaron y me dejaron. Porque así como me trajeron me tendrían que haber llevado. No tenía plata para volver, nada. Salí y pedí laburo acá en una obra, me dieron laburo, después estuve laburando en un campo. $Y$ después me cansé de laburar ahí y me fui a pedir laburo a donde estoy ahora, en el '84. (H. D. INALEF, 2016, información oral)

Tras la liberación, Héctor cuenta que intentó comunicarse alguna vez con su familia, motivo por el cual acudió a la misma comisaría pero "no te daban bolilla". Tampoco tuvo suerte en el correo, donde le requerían una casilla postal que él desconocía. La prioridad era trabajar para comer y tener dónde dormir, y si bien recuerda 
En septiembre de 1983, en plena reapertura democrática, Héctor oficializó en su DNI el cambio de domicilio a Viedma, donde algunos años más tarde formaría familia. Excepto con sus hijos y un cliente del local en el que trabajaba y que luego no volvió a ver, Héctor nunca había compartido, hasta ahora, su historia con nadie.

\section{Reflexiones finales}

Desde la perspectiva de la historia oral y los estudios sobre memorias, y a través de un entramado de testimonios orales y documentales, este artículo ha abordado el caso de Héctor Domingo Inalef, detenido en la frontera cordillerana rionegrina por supuesta deserción al servicio militar en 1976, y desde entonces "desaparecido" hasta reencontrarse con su familia en 2014. Hijo mayor y principal sostén económico de una familia mapuche y empobrecida tradicionalmente dedicada a tareas agropecuarias, su historia permite profundizar la reflexión sobre la desaparición forzada en nuestro país, la superposición de la represión con las marcas de la desigualdad social, y las implicancias políticas y memoriales de la pobreza y la ruralidad en la frontera patagónica, tanto en tiempos dictatoriales como democráticos.

Su "aparición con vida" pone de manifiesto dimensiones tan novedosas como constitutivas y reveladoras del carácter sistemático del terrorismo de Estado en estas latitudes.

En primer lugar, la articulación del relato público pone de manifiesto una historia insospechada en los marcos de significación hegemónicos, que logró trascender en el tiempo de manera subterránea hasta salir a la luz desafiando tales límites. Lejos de tratarse de un militante político y más aún de identificarse con la clase media urbana, Héctor pertenecía a los sectores empobrecidos de una comunidad rural de frontera, y, a diferencia de los casos abordados por Diana Lenton (2018), quien trabaja el vínculo entre activismo indígena y dictadura, su identidad mapuche no estaba siendo activamente 
reivindicada. De su historia nada supo la sociedad local, dado que, producto de la desarticulación del mundo indígena tras las campañas militares de fines del siglo XIX y los procesos de descomposición que fueron tejiendo las circunstancias ulteriores, su familia no contaba siquiera con los recursos materiales o simbólicos necesarios para reclamar ante las violencias ni demandar verdad y justicia.

En segundo lugar, la historia de Héctor y su familia nos muestra la superposición de la represión con las marcas de la desigualdad social, al tiempo que evidencia la distancia de estos grupos con el Estado y aún con el movimiento de derechos humanos, instalando la mirada sobre actores que no forman parte de la polis y, con ello, el problema y la dimensión política de la desigualdad, la ignorancia y el desamparo. De hecho, el caso evoca la innumerable cantidad de víctimas aún "doblemente desaparecidas”, en cuanto no sólo sus familias desconocen durante décadas, sino para siempre, la suerte por ellas corrida, sino que además sus casos no figuran en las burocracias estatales, con la restricción de derechos que esto indefectiblemente supone, ni de los organismos de derechos humanos, dado que la falta de recursos simbólicos y sociales necesarios impidió llevar adelante acción judicial o política alguna para dar con su paradero. Algo que, como hemos visto, puede ser revertido en la medida en que confluyen circunstancias que hacen decible la experiencia, haciendo aparecer la historia al enmarcarla en una clave de lectura determinada para descifrarla, en este caso como desaparición forzada.

En tercer lugar, el caso permite reflexionar sobre los límites que la ruralidad y la pobreza imponen para el ejercicio de la ciudadanía en zonas fronterizas, más aún en tiempos de largas distancias y poca comunicación con el centro urbano, traslados en carros tirados con bueyes o a caballo, en los que la autoridad estatal no se cuestionaba, por lo general era sumamente abusiva y la prepotencia estaba naturalizada, obturando toda posibilidad de denuncia de las injusticias que se cometieran, más allá y más acá de gobiernos dictatoriales. Sumado a la acusación de conscripto desertor y el sometimiento a las violencias propias de ese código castrense, agrega complejidad a la reflexión el carácter mapuche de la(s) víctima(s), toda vez que, tal como señalara Tozzini (2012), la identificación de personajes y situaciones liminares nos permite trascender la 
simplificación binaria de la historia y así dar cuenta de cercanías, alejamientos, disensos y decisiones respecto del mundo indígena. De este modo, también,

[...] mostrar otras formas - tal vez más realistas - en las cuales aquel pasado de la conquista del Desierto con el cual nos topamos en la Patagonia a cada vuelta de la esquina, se sigue entramando con el presente de maneras diferenciales. Tan disímiles como los sujetos que las cargan a sus espaldas... (TOZZINI, 2012, p. 271).

El caso de Héctor Domingo Inalef nos muestra la potencialidad de la historia oral como herramienta y fundamento de la tarea investigativa, así como el compromiso ético y político que supone, más aún cuando se trata de nuestra historia reciente. Como señala Pollak (2006), hacer historia oral requiere una sensibilidad epistemológica agudizada, que se amplifica toda vez que, más allá de los datos objetivos que pueda aportar sobre los acontecimientos que se busca conocer, pone en evidencia los límites del trabajo de encuadramiento, habilitando una multiplicidad novedosa de significados y gramáticas a las vivencias de los protagonistas, con el potencial impacto que esto supone para incidir sobre la realidad y su eventual transformación, y, desde ya, sobre la propia identidad. De hecho, asistimos a la contingencia de la historia cuando, casi cuatro décadas más tarde, confluyen circunstancias como la posibilidad de terminar la escuela primaria, la inclusión del tema en el plan de estudios, la utilización de estrategias didácticas como la radio o la participación en encuentros de mujeres, trama que le fue permitiendo a Zunilda construir un cauce nuevo por donde canalizar esa "sensación fea" que no se podía sacar de encima. Fue la escuela de adultos la que le habilitó el acceso a ese capital cultural y social necesario para que esta búsqueda pudiera efectivamente convertirse en tal, activando los resortes sociales, familiares y burocráticos adecuados para lograr que suceda. Y, a partir de entonces, comenzar a iluminar y ensanchar las grietas del poder.

La perspectiva microhistórica nos permite, pues, abarcar nuevos pliegues de un fenómeno tan complejo como lo es el de la represión y la violencia estatal en general, y la desaparición en particular, toda vez que casos como el de Héctor exponen la necesidad de construir una memoria del terrorismo de Estado en clave local, rural e indígena, que dé cuenta del saqueo, la explotación y la subordinación a la que fueron sometidos grandes 
Nacional de Seguridad Social (ANSES); su testimonio ha sido incorporado al archivo de la Secretaría de Derechos Humanos, lo cual aporta nuevas aristas al trabajo del organismo tanto en los ámbitos judiciales, como educativos y de promoción de derechos en la provincia; y Zunilda y sus hijas Ilevan adelante el proceso de recuperación territorial amparadas por la ley indígena y las comunidades mapuche de la región. Aún tarde en muchos aspectos, y en absoluto reparador de las injusticias estructurales de la historia, quizás la consecución del trámite en la ANSES, la apropiación de la causa por parte del organismo provincial, y la recuperación territorial de al menos parte del campo de la familia Inalef, contengan en sí mismas gran parte de la carga simbólica que supone lograr el reconocimiento por parte del Estado argentino de su responsabilidad indelegable en la garantía de los derechos humanos del conjunto de la sociedad, especialmente para con los sectores más postergados de nuestro pueblo.

\section{Referencias}

ARGENTINA. Ley No. 17.531, de 13 de noviembre de 1967. Ley de Servicio Militar. Boletín Oficial de la República Argentina, Buenos Aires, 16 nov. 1967.

BANDIERI, Susana. Cuando crear una identidad nacional en los territorios patagónicos fue prioritario. Revista Pilquen: Sección Ciencias Sociales, Viedma, v. 11, n. 11, p. 1-5, 2009.

CALVEIRO, Pilar. Poder y desaparición: los campos de concentración en Argentina. Buenos Aires: Colihue, 1998. (Colección Puñaladas).

COLOMBO, Pamela. Espacios de desaparición: vivir e imaginar los lugares de la violencia estatal (Tucumán, 1975-1983). Buenos Aires: Miño y Dávila, 2017.

CRENZEL, Emilio. La historia política del Nunca Más: la memoria de las desapariciones en la Argentina. Buenos Aires: Siglo XXI, 2008. 
DEL PINO, Ponciano; JELIN, Elizabeth (Comp.). Luchas locales, comunidades e

identidades. Madrid: Siglo XXI, 2003. (Colección Memorias de la Represión).

DOCUMENTO NACIONAL DE IDENTIDAD de Héctor Domingo Inalef

FRANCO Marina; LEVIN, Florencia (Comp.). Historia reciente: perspectivas y desafíos para un campo en construcción. Buenos Aires: Paidós, 2007. (Colección Espacios del Saber).

GARAÑO, Santiago. Soberanía, estado de excepción y seres matables en el teatro de operaciones del Operativo Independencia (Tucumán, Argentina, 1975-1977). Runa, Buenos Aires, v. 37, n. 2, p. 5-24, 2016.

GINZBURG, Carlo. Microhistoria: dos o tres cosas que sé de ella. Manuscrits, Barcelona, $\mathrm{n}$. 12, p. 13-42, 1994.

INALEF, Héctor Domingo. [Testimonio dado a] Secretaría de Derechos Humanos de Río Negro, Viedma, 11 nov. 2015.

INALEF, Héctor Domingo. [Entrevista dada a] Ayelén Mereb, Viedma, 23 mayo 2016.

INALEF, Zunilda. [Entrevista dada a] Iris Abarzúa, El Bolsón, mar. 2013.

INALEF, Zunilda. [Entrevista dada a] Ayelén Mereb, Mallín Ahogado, 27 feb. $2014 a$.

INALEF, Zunilda. [Entrevista dada a] Ayelén Mereb e Iris Abarzúa, Mallín Ahogado, ago. 2014b.

JENSEN, Silvina; ÁGUILA, Gabriela (Coord.). Dossier la historia reciente más allá de lo nacional: Cono Sur y Península Ibérica. Clepsidra, Buenos Aires, v. 4, n. 7, p. 6-13, 2017.

LAMPASONA, Julieta. Desaparición forzada en Argentina: entre la desaparición y la sobrevida. O sobre la "regla" y la "excepción" en el despliegue de la tecnología de poder genocida. Aletheia, La Plata, v. 3, n. 6, p. 1-20, 2013.

LENTON, Diana. De genocidio en genocidio. Notas sobre el registro de la represión a la militancia indígena. Revista de Estudios sobre Genocidio, Buenos Aires, v. 13, n. 9, p. 4761, 2018.

LEVI, Giovanni. Sobre microhistoria. In: BURKE, Peter. Formas de hacer historia. Madrid: Alianza, 1996. p. 119-143.

LIBRO HISTÓRICO ESCUELA N¹18, Mallín Ahogado, El Bolsón, Río Negro, 1938. 
MENDEZ, Laura (Dir.). Historias en movimiento. Cuerpo, educación y tiempo libre en la Norpatagonia, 1884-1945. Rosario: Prohistoria, 2011.

MEREB, Ayelén. El movimiento de derechos humanos y la construcción de las memorias de la represión en clave local. La resistencia "jipuche" en El Bolsón de la posdictadura argentina. Nuevo Mundo Mundos Nuevos. 2018. Disponible en:

<http://journals.openedition.org/nuevomundo/72891>. Acceso en: 25 sep. 2019.

MERENSON, Silvina; GARAÑO, Santiago (Coord.). Dossier Memorias Rurales: avances y desafíos para los estudios sobre el pasado reciente en América Latina. Clepsidra, Buenos Aires, v. 2, n. 3, p. 5-29, 2015.

POLLAK, Michael. Memoria, olvido, silencio: la producción social de identidades frente a situaciones límite. La Plata: Al Margen, 2006.

RAMOS, Ana; CRESPO, Carolina; TOZZINI, Alma. Memorias en lucha: recuerdos y silencios en contextos de subordinación y alteridad. Viedma: Universidad Nacional de Río Negro, 2016.

SALES, Naco. El Bolsón de antes. El Bolsón: [s.n.], 2002.

SCATIZZA Pablo. La detención clandestina más allá de los “campos de concentración”. Aportes analíticos a una clave explicativa canónica de la Argentina dictatorial. Nuevo Mundo Mundos Nuevos. 2019. Disponible en: <http://journals.openedition.org/ nuevomundo/75993>. Acceso en: 25 sep. 2019.

TOZZINI, María Alma. Pudiendo ser mapuche. Reclamos territoriales, procesos identitarios y Estado en Lago Puelo. Provincia del Chubut. Tesis (Doctorado en Antropología Social) - Universidad de Buenos Aires, Facultad de Filosofía y Letras, Buenos Aires, p. 293, 2012. 